\section{Vegetative Growth of Potato under High- pressure Sodium, High-pressure Sodium SON-Agro, and Metal Halide Lamps}

\author{
N.C. Yorio and C.L. Mackowiak \\ Dynamac Corporation, Mail Code DYN-3, Kennedy Space Center, FL 32899 \\ R.M. Wheeler and J.C. Sager \\ National Aeronautics and Space Administration Biomedical Operations and \\ Research Office, Mail Code MD-RES, Kennedy Space Center, FL 32899
}

Additional index words. Solanum tuberosum, blue light, stem elongation, internode length, spectral quality, photomorphogenesis

\begin{abstract}
Potato (Solanum tuberosum L.cvs. Norland and Denali) plants were grown under high-pressure sodium (HPS), metal halide (MH), and blue-light-enhanced SON-Agro high-pressure sodium (HPS-S) lamps to study the effects of lamp spectral quality on vegetative growth. All plants were initiated from in vitro nodal cultures and grown hydroponically for 35 days at $300 \mu \mathrm{mol} \cdot \mathrm{m}^{-2} \cdot \mathrm{s}^{-1}$ photosynthetic photon flux (PPF) with a 12 hour light/12-hour dark photoperiod and matching 20C/16C thermoperiod. 'Denali' main stems and internodes were significantly longer under HPS compared to MH, while under HPS-S, lengths were intermediate relative to those under other lamp types, but not significantly different. 'Norland' plants showed no significant differences in stem and internode length among lamp types. Total dry weight of 'Denali' plants was unaffected by lamp type, but 'Norland' plants grown with HPS had significantly higher dry weight than those under either HPS-S or MH. Spectroradiometer measurements from the various lamps verified the manufacturer's claims of a $30 \%$ increase in ultraviolet-blue (350 to 450 nm) output from the HPS-S relative to standard HPS lamps. However, the data from 'Denali' suggest that at $300 \mu \mathrm{mol} \cdot \mathrm{m}^{-2} \cdot \mathrm{s}^{-1}$ total PPF, the increased blue from HPS-S lamps is still insufficient to consistently maintain short stem growth typical of blue-rich irradiance environments.
\end{abstract}

The use of high-intensity discharge lamps, particularly high-pressure sodium (HPS), for plant growth-chamber lighting has become increasingly popular because of their high conversion efficiencies of electrical power into photosynthetically active radiation (Sager et al., 1982; Tibbitts et al., 1983). However, the spectral output of HPS lamps is relatively deficient in the near-ultraviolet (UV) (350 to $400 \mathrm{~nm}$ ) and blue (400 to $500 \mathrm{~nm}$ ) wavelengths, which can be a concern for morphological development of some plant species. For example, exposure to low levels of nearUV radiation can prevent development of oedema (intumescence), a physiological disorder in certain plants (Lang and Tibbitts, 1983), while the lack of blue light can cause

Received for publication 21 Apr. 1994. Accepted for publication 10 Sept. 1994. We thank Dale Brabham, Philips Lighting Corp., for providing the HPS SON-Agro lamps for testing; Lisa Ruffe for horticultural assistance in conducting these studies; and Joe Martinez and Joe Benjamin for growth chamber maintenance. Mention of a trade name does not constitute an endorsement by either the National Aeronautics and Space Administration or The Bionetics Corp. The cost of publishing this paper was defrayed in part by the payment of page charges. Under postal regulations, this paper therefore must be hereby marked advertisement solely to indicate this fact.

excessive hypocotyl and stem elongation (Britz and Sager, 1990; Cosgrove, 1981; Tibbitts et al., 1983; Wheeler et al., 1991a). Evidence suggests blue light influences stem growth quantitatively, with a minimum level of 25 to $30 \mu \mathrm{mol} \cdot \mathrm{m}^{-2} \cdot \mathrm{s}^{-1}$ blue photon flux needed to prevent excessive elongation of soybean ( Glycine $\max \mathrm{L}$.) stems and normal shoot development of lettuce (Lactuca sativa L.) (Britz and Sager, 1990; Bula et al., 1991; Wheeler et al., 1991a).

The influence of spectral quality on plant growth and development is a particular concern for the crops used in controlled ecological of 350 to $700 \mathrm{~nm}$ and 400 to $700 \mathrm{~nm}$, respectively. flux. life support systems (CELSS) in space (Langhans and Dreesen, 1988). In a CELSS, the crops could be grown in controlled environments, likely with electric lighting, to produce food and $\mathrm{O}_{2}$, while removing waste $\mathrm{CO}_{2}$ from the atmosphere. For all CELSS crops, high productivities coupled with short shoot stature are highly desirable, since yields must ultimately be compared three-dimensionally, i.e., $\mathrm{g} \cdot \mathrm{m}^{-3} \cdot \mathrm{day}^{-1}$, rather than $\mathrm{g} \cdot \mathrm{m}^{-2} \cdot \mathrm{day}^{-1}$. Tall crops would require more volume to produce, which would translate into significantly higher costs for launching a containment vessel (Drysdale et al., 1993). Possible strategies for minimizing shoot growth might include selection of high-yielding dwarf cultivars, use of growth regulators, or environmental manipulations (e.g., temperature, photoperiod, spectral quality). We were particularly interested in the influence of spectral quality for height control, since spectral effects can be used in conjunction with any adapted cultivar and would avoid the need for chemical regulators or environmental changes that might reduce productivity (e.g., cooler temperatures or shorter photoperiods). A new type of HPS lamp, the HPS SON-Agro (HPS-S), has recently been developed that provides slightly more blue than a standard HPS, and thus has the high efficiency of a sodium lamp but with a slightly broader spectrum (Philips Lighting, 1990). Our objective was to determine whether HPS-S can be used to reduce stem growth of potato plants in comparison to standard HPS lamps.

\section{Materials and Methods}

'Norland' (early maturing red) and 'Denali' (late-maturing white) potato plants were initiated from in vitro nodal culture and grown for 35 days using a recirculating nutrient film technique (NFT) (Wheeler et al., 1990). Each study, consisting of one cultivar with one lamp type, was conducted in separate reach-in plant growth chambers (model M12; EGC, Chagrin Falls, Ohio) using a total of four plants per study, with each study repeated once (two replications of four plants each). At harvest, plant height (main stem length) and number of nodes were measured and the average internodal length calculated. Total plant dry matter

Table 1. Light source and average weekly photon flux levels used to study potato stem elongation. ${ }^{2}$

\begin{tabular}{|c|c|c|c|}
\hline \multirow[b]{2}{*}{$\begin{array}{l}\text { Cultivar and } \\
\text { lamp }^{x}\end{array}$} & \multicolumn{3}{|c|}{ Photon flux $\left(\mu \mathrm{mol} \cdot \mathrm{m}^{-2} \cdot \mathrm{s}^{-1}\right)$} \\
\hline & $\begin{array}{l}\text { Photosynthetic } \\
(400-700 \mathrm{~nm})\end{array}$ & $\begin{array}{c}\text { UV-blue } \\
(350-450 \mathrm{~nm})\end{array}$ & $\begin{array}{c}\text { Blue } \\
(400-500 \mathrm{~nm})\end{array}$ \\
\hline \multicolumn{4}{|l|}{ Denali } \\
\hline HPS & 311 & $6.2(100)^{\mathrm{w}}$ & $19.7(100)$ \\
\hline HPS-S & 299 & $7.6(127)$ & $21.1(112)$ \\
\hline $\mathrm{MH}$ & 285 & $42.5(745)$ & $64.6(358)$ \\
\hline \multicolumn{4}{|l|}{ Norland } \\
\hline HPS & 311 & $6.2(100)$ & $19.7(100)$ \\
\hline HPS-S & 280 & $7.1(127)$ & $19.8(112)$ \\
\hline $\mathrm{MH}$ & 283 & $42.2(745)$ & $64.1(358)$ \\
\hline
\end{tabular}

${ }^{2}$ UV-blue and blue photon fluxes determined from integrations of lamp spectral scans within the band widths

yUV-blue (350 to $450 \mathrm{~nm}$ ) band width analyzed for comparison to manufacturer's claims.

${ }^{x} \mathrm{HPS}=$ high-pressure sodium; HPS-S = high-pressure sodium SON-Agro; $\mathrm{MH}=$ metal halide.

wPercentage based on HPS photon fluxes $(100 \%)$ normalized to $300 \mu \mathrm{mol} \cdot \mathrm{m}^{-2} \cdot \mathrm{s}^{-1}$ photosynthetic photon 
(shoots, roots, stolons, and small tubers) was determined after plant tissue was oven-dried at $70 \mathrm{C}$ for at least $48 \mathrm{~h}$. For each cultivar, mean separation was performed using Scheffe's test to determine if significant differences existed.

Environmental conditions consisted of a 12-h light/12-h dark photoperiod with a matching thermoperiod of $19.9 \pm 0.2 \mathrm{C} / 16.0 \pm 0.2 \mathrm{C}$ and a constant relative humidity of $65 \% \pm 3 \% /$ $69 \% \pm 4 \%$. Atmospheric $\mathrm{CO}_{2}$ was maintained at $1000 \mu \mathrm{mol} \cdot \mathrm{mol}^{-1}$ to promote rapid growth.

Lighting for each treatment was provided with one of the following lamp types: 1) four 400-W HPS lamps (Lucalox; General Electric Co., Cleveland); 2) four 430-W HPS (HPS-S) lamps (SON-Agro; Philips Lighting Co. Somerset, N.J.), or 3 ) four 400-W metal halide (MH) lamps (Pro-Arc; Venture Lighting, Cleveland). Plants grown under $\mathrm{MH}$ lamps were assumed to represent growth typical of a broad-spectrum light environment. Total photosynthetic photon flux (PPF) for all treatments was measured weekly and maintained near $300 \mu \mathrm{mol} \cdot \mathrm{m}^{-2} \cdot \mathrm{s}^{-1}$ (Table 1) by placing stainless steel screens atop the lamp barrier in the chamber. Also measured were the photon fluxes in the 350- to 450-nm (UV-blue) and 400- to 500-nm (blue) band widths. All spectral data were measured with a spectroradiometer (LI-1800; LI-COR, Lincoln, Neb.).

\section{Results and Discussion}

Spectroradiometer scans of the lamps showed that HPS-S lamps provided $12 \%$ more blue ( 400 to $500 \mathrm{~nm}$ ) radiation than HPS lamps (Table 1). For comparison, the analysis of the 350- to 450-nm band width (UV-blue) had $27 \%$ more UV-blue than standard HPS lamps, which generally agrees with the manufacturer's claims (Philips Lighting, 1990). This amounted to $\approx 7 \%$ of the total PPF being in the blue, as compared to $\approx 6 \%$ for the standard HPS lamp. Pro-Arc MH lamps had $\approx 23 \%$ of their PPF in the blue region. Thus, although the HPS-S lamps had $12 \%$ more blue than standard HPS lamps, this amounts to only 1 to $2 \mu \mathrm{mol} \cdot \mathrm{m}^{-2} \cdot \mathrm{s}^{-1}$ additional blue photon flux out of a total PPF of $300 \mu \mathrm{mol} \cdot \mathrm{m}^{-2} \cdot \mathrm{s}^{-1}$. Although this difference is small, it may still be significant with regard to plant growth if the total amount of blue is near the minimum requirement.

Stems and internodes were longest with 'Denali' plants grown under HPS lamps (Fig. 1). HPS-grown plants had significantly longer stems and internodes than MH-grown plants, but HPS-S plants were not significantly different from either HPS or MH. The results suggest that for 'Denali', the slight increase in blue radiation from the HPS-S was not sufficient to completely overcome the stem elongation induced in plants grown under HPS (Wheeler et al., 1991a). Thus, the blue photon flux of $21.1 \mu \mathrm{mol} \cdot \mathrm{m}^{-2} \cdot \mathrm{s}^{-1}$ (Table 1) may still have been below the minimum level of blue radiation needed to give a maximum response.

Stem length of 'Norland' plants was unaffected by lamp type, indicating that there may be genetic differences between cultivars with regard to spectral effects on stem growth (Fig. 1). The lack of significant differences may
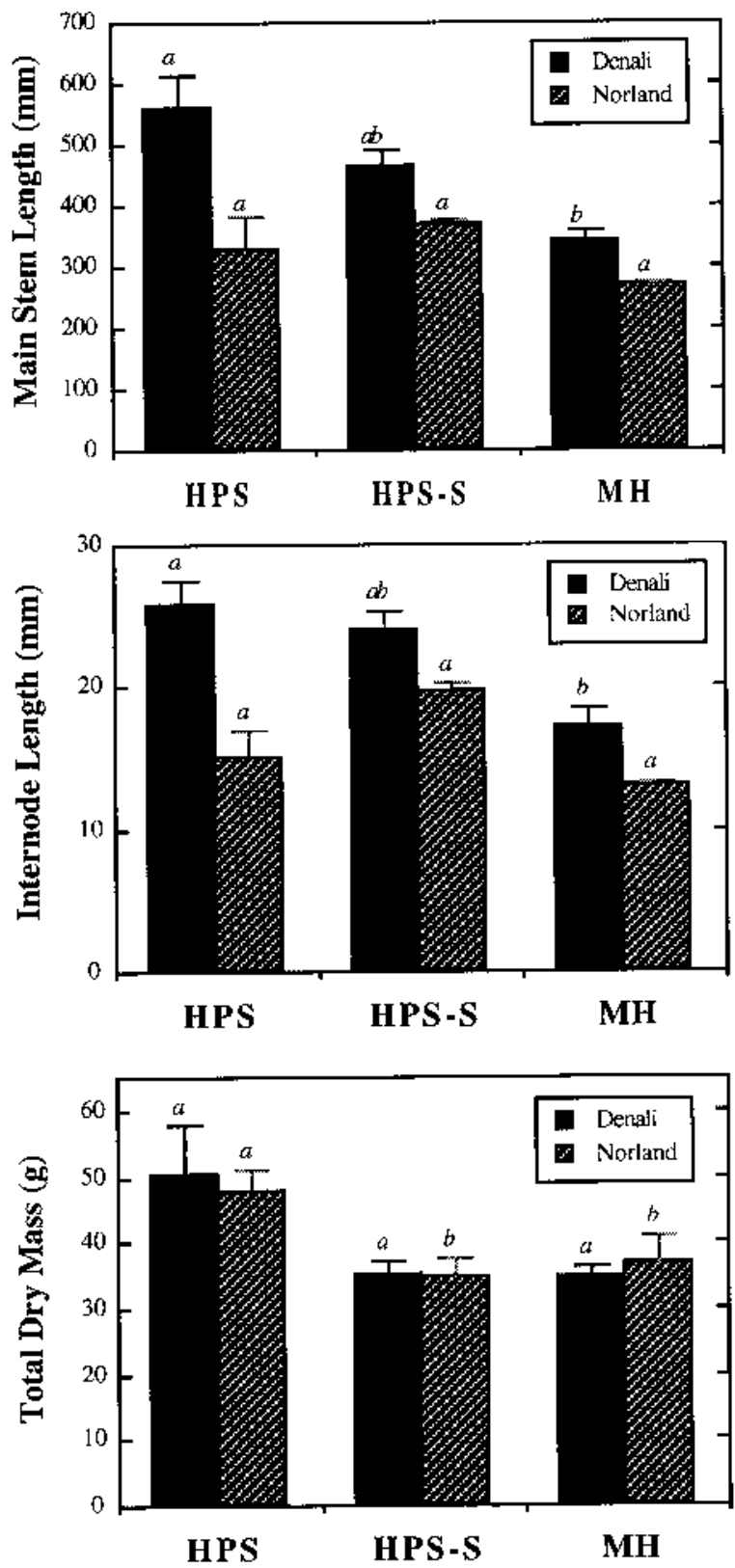

Fig. 1. Lamp type effects on the vegetative growth of 'Denali' and 'Norland' potatoes. For each cultivar, means separation as determined by Scheffe's test is represented by letters. Each cultivar was tested separately. Vertical lines $=\mathrm{SE}$.

indicate the amount of blue even in the standard HPS $\left(19.7 \mu \mathrm{mol} \cdot \mathrm{m}^{-2} \cdot \mathrm{s}^{-1}\right)$ was sufficient to maintain short stem growth in 'Norland', or alternatively, other environmental factors (e.g. an inductive, short photoperiod) may have had an overriding influence on shoot growth (Wheeler et al., 1991b).

Total plant dry matter for 'Norland' was highest with HPS lamps (Fig. 1), while dry matter for 'Denali' showed no significant difference between lamp types. Average PPF values for the HPS treatments for both cultivars were slightly higher than for the other treatments; thus, the increased biomass from the HPS treatments may have been due primarily to increased total irradiance. However, other studies have demonstrated increased growth with HPS lamps in comparison to broad-spectrum fluorescent or MH lamps (Koontz et al., 1987; Wheeler et al., 1994).
We have shown that stem elongation of 'Denali' is significantly greater under HPS than under MH lamps when total PPF is near $300 \mu \mathrm{mol} \cdot \mathrm{m}^{-2} \cdot \mathrm{s}^{-1}$, but there was no effect of lamp type on stem elongation of 'Norland'. The trend, although not significant, in the growth response of 'Denali' under HPS-S lamps suggests that stem elongation might be reduced by use of HPS-S in place of standard HPS lamps, indicating the minimum blue light requirement for preventing excessive stem elongation may be $>20 \mu \mathrm{mol} \cdot \mathrm{m}^{-2} \cdot \mathrm{s}^{-1}$. Further testing at various total PPF and blue photon flux levels (e.g., between 10 and $30 \mu \mathrm{mol} \cdot \mathrm{m}^{-2} \cdot \mathrm{s}^{-1}$ blue) is needed to determine whether there is a minimum blue light requirement for stem growth in potato, and to define better the total PPF ranges where HPS-S might be effective for morphological growth control. 


\section{Literature Cited}

Britz, S.J. and J.C. Sager. 1990. Photomorphogenesis and photoassimilation in soybean and sorghum grown under broad spectrum or bluedeficient light sources. Plant Physiol. 94:448454.

Bula, R.J., R.C. Morrow, T.W. Tibbitts, R.W. Ignatius, T.S. Martin, and D.J. Barta. 1991. Light-emitting diodes as a radiation source for plants. HortScience 26:203-205.

Cosgrove, D.J. 1981. Rapid suppression of growth by blue light. Occurrence, time course, and general characteristics. Plant Physiol. 67:584590.

Drysdale, A., J. Sager, R. Wheeler, R. Fortson, and P. Chetirkin. 1993. CELSS engineering parameters. Soc. Automotive Eng. Tech. Paper Ser. 932130, Soc. Automotive Eng., Colorado Springs, Colo.
Koontz, H.V., R.P. Prince, and R.F. Koontz. 1987. Comparison of fluorescent and high-pressure sodium lamps on growth of leaf lettuce. HortScience 22:424-425.

Lang, S.P. and T.W. Tibbitts. 1983. Factors controlling intumescence development on tomato plants. J. Amer. Soc. Hort. Sci. 108:93-98.

Langhans, R.W. and D.R. Dreesen. 1988. Challenges for plant growing in space. HortScience 23:286-293.

Philips Lighting. 1990. Grow with a new spectrum of light P-2708. Philips Lighting Corp., Somerset, N.J.

Sager, J.C., J.L. Edwards, and W.H. Klein. 1982. Light energy utilization efficiency for photosynthesis. Trans. Amer. Soc. Agr. Eng. 25:17371746.

Tibbitts, T.W., D.C. Morgan, and I.J. Warrington. 1983. Growth of lettuce, spinach, mustard, and wheat plants under four combinations of high- pressure sodium, metal halide, and tungsten halogen lamps at equal PPFD. J. Amer. Soc. Hort. Sci. 108:622-630.

Wheeler, R.M., C.L. Mackowiak, and J.C. Sager. 1991a. Soybean stem growth under high-pressure sodium with supplemental blue lighting. Agron. J. 83:903-906.

Wheeler, R.M., C.L. Mackowiak, J.C. Sager, W.M. Knott, and C.R. Hinkle. 1990. Growth of potatoes using nutrient film technique (NFT). Amer. Potato J. 67:177-187.

Wheeler, R.M., C.L. Mackowiak, J.C. Sager, N.C. Yorio, W.M. Knott, and W.L. Berry. 1994. Growth and gas exchange by lettuce stands in a closed, controlled environment. J. Amer. Soc. Hort. Sci. 119:610-615.

Wheeler, R.M., T.W. Tibbitts, and A.H. Fitzpatrick. 1991b. Carbon dioxide effects on potato growth under different photoperiods and irradiance. Crop Sci. 31:1209-1213. 